\title{
Editorial
}

\section{Heterojunction Solar Cells}

\author{
Aung Ko Ko Kyaw, ${ }^{1}$ Antonio Otavio T. Patrocinio, ${ }^{2}$ Dewei Zhao, ${ }^{3}$ and Victor Brus ${ }^{4}$ \\ ${ }^{1}$ Institute of Materials Research and Engineering (A* STAR), 3 Research Link, Singapore 117602 \\ ${ }^{2}$ Institute of Chemistry, Federal University of Uberlandia, Uberlandia, MG, Brazil \\ ${ }^{3}$ Department of Electrical Engineering and Computer Science, the University of Michigan, Ann Arbor, MI 48109, USA \\ ${ }^{4}$ Department of Electronics and Energy Engineering, Chernivtsi National University, Chernivtsi 58000, Ukraine
}

Correspondence should be addressed to Aung Ko Ko Kyaw; aung0069@ntu.edu.sg

Received 11 August 2014; Accepted 11 August 2014; Published 24 August 2014

Copyright ( 2014 Aung Ko Ko Kyaw et al. This is an open access article distributed under the Creative Commons Attribution License, which permits unrestricted use, distribution, and reproduction in any medium, provided the original work is properly cited.

With endless energy demand and climate change issue, solar cells which convert sun light directly into electricity are becoming increasingly important in the world's renewable energy mix. The development of new solar cell technologies with lower production costs is therefore of great interest to industry. New and prospective materials are under intensive research in order to create low cost and highly efficient photovoltaic devices based on various organic, hybrid organicinorganic, and inorganic heterojunctions. Heterojunction solar cells possess a combination of unique properties of different materials that helps to improve their operational characteristics comparing with traditional homojunction silicon solar cells.

In this special issue, we selected 6 peer-reviewed research articles which present the recent developments in various types of heterojunction solar cells, including organic bulkheterojunction solar cells, dye/quantum dot sensitized solar cells, hybrid organic-inorganic solar cells, and inorganic heterojunction solar cells. A broad range of topics, from material synthesis and thin film deposition technique to device architecture, are discussed in this special issue. A brief overview of each paper highlighting the key result and discovery is as follows.

In the paper "Design of a free-ruthenium $\operatorname{In}_{2} S_{3}$ crystalline photosensitized solar cell," a new sulfide-based solid state sensitizer was assessed as a potential replacement for traditional Ru-based dyes. The morphology of $\operatorname{In}_{2} \mathrm{~S}_{3}$ on $\mathrm{TiO}_{2}$ films was investigated and the role of its concentration on the overall conversion efficiency of DSCs was discussed.
The paper "Nanopatterned silicon substrate use in heterojunction thin film solar cells made by magnetron sputtering" proposed a method for the fabrication of novel nanopatterned silicon heterojunction thin film solar cells ITO/p-type a-Si:H/n-type c-Si. The nanopatterned silicon wafers with a self-assembled monolayer of $\mathrm{SiO}_{2}$ nanospheres $550 \mathrm{~nm}$ in diameter were used in order to achieve $31.49 \%$ higher efficiency comparing to that of heterojunction solar cells based on planar silicon substrates.

In "Doped heterojunction used in quantum dot sensitized solar cell," quantum dot sensitized solar cells with indiumdoped $\mathrm{PbS} / \mathrm{CdS}$ QDs forming In-PbS/In-CdS heterojunction were presented by successive ionic layer adsorption and reaction method. Such an incorporation results in the light harvesting of heterojunction, leading to enhanced device performance.

In "Excellent silicon surface passivation achieved by industrial inductively coupled plasma deposited hydrogenated intrinsic amorphous silicon suboxide," authors present an alternative method of depositing a high-quality passivation film for silicon solar cells. The deposition of hydrogenated intrinsic amorphous silicon suboxide was accomplished by decomposing hydrogen, silane, and carbon dioxide in an industrial remote inductively coupled plasma platform. Through the precise control of $\mathrm{CO}_{2}$ partial pressure and process temperature, excellent surface passivation quality and optical properties were achieved.

In the paper "Ultrathin anode buffer layer for enhancing performance of polymer solar cells," an enhanced polymer 
solar cell was achieved by adding an ultrathin layer of lithium fluoride in between PEDOT:PSS and polymer active layer. The dominant mechanism for performance improvement was explained as the increased charge collection by anode buffer layers.

In the paper "The promotion of the efficiency of organic photovoltaic devices by addition of anisotropic CdSe nanocrystals," CdSe nanocrystals with different morphologies such as tetrapod and nanorod were synthesized by seed growth method and applied as the acceptor in the active layer of the organic photovoltaic (OPV) devices. When the concentration of CdSe in P3HT: PCBM system is $50 \mathrm{wt} \%$ optimally, the efficiency can be promoted about $4.3 \%$.

We do believe that the collection of papers from multidisciplinary areas will benefit the community of heterojunction solar cell research for the further development of this research area.

\section{Acknowledgments}

We would like to express our sincere appreciation to all the authors for submitting their exciting scientific results to this special issue. We are also grateful to all the reviewers around the world, whose dedicated efforts and high-quality work have made this issue possible. Last but not least, we would like to thank the editorial board of International Journal of Photoenergy for giving us opportunity to publish this special issue.

Aung Ko Ko Kyaw Antonio Otavio T. Patrocinio Dewei Zhao Victor Brus 

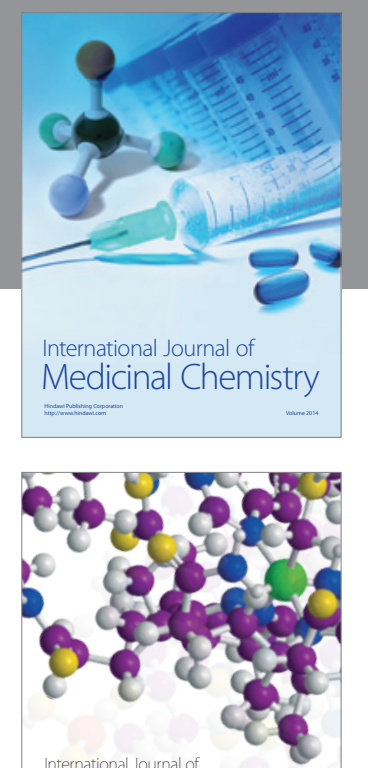

\section{Carbohydrate} Chemistry

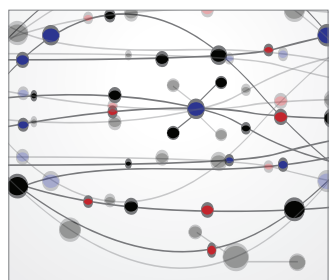

The Scientific World Journal
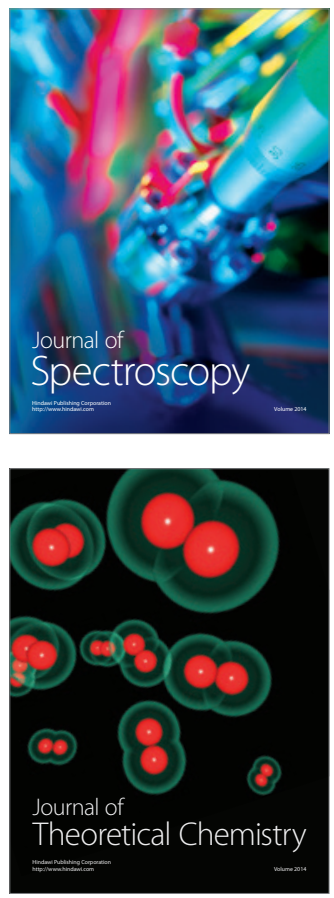
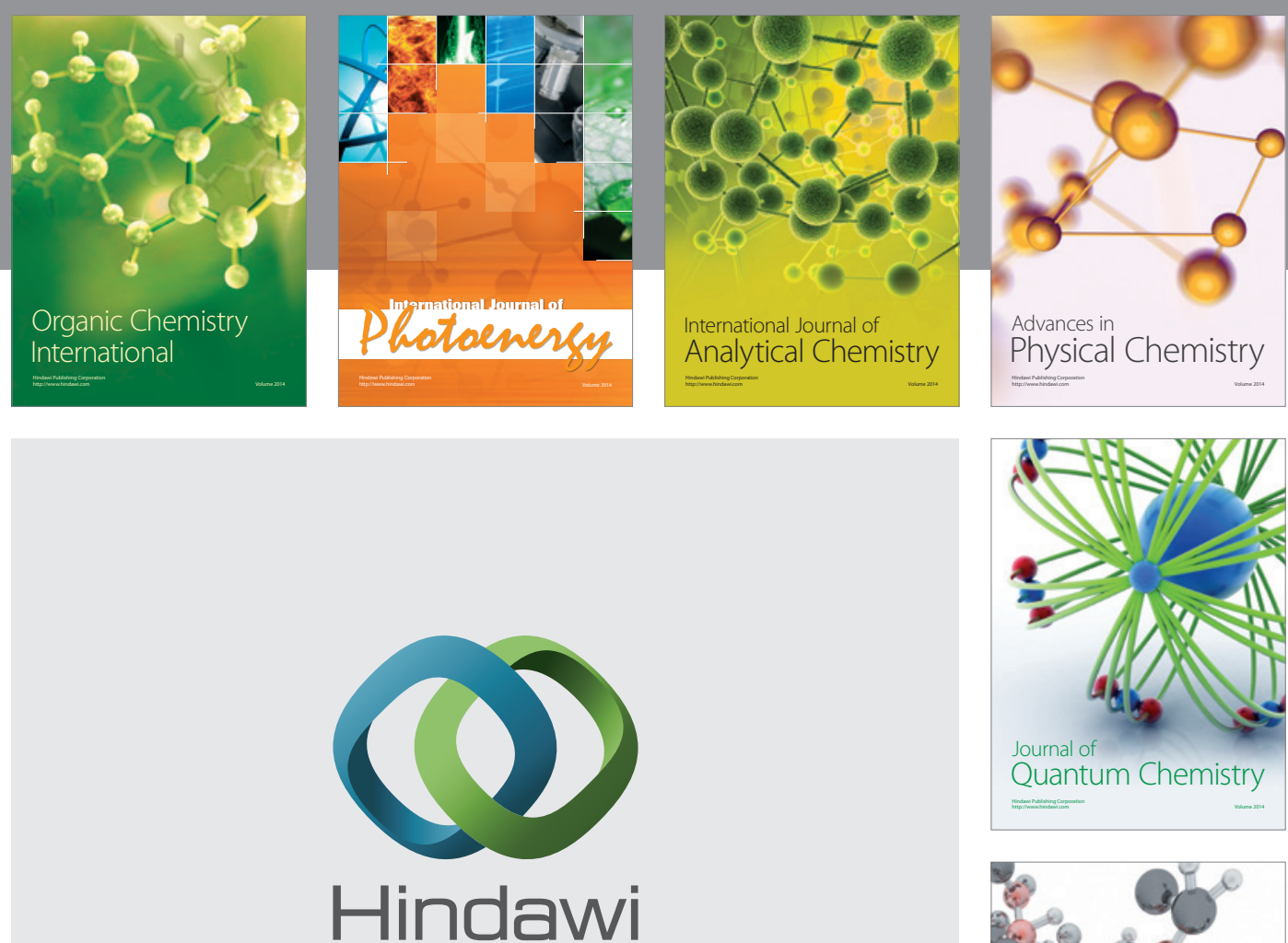

Submit your manuscripts at

http://www.hindawi.com

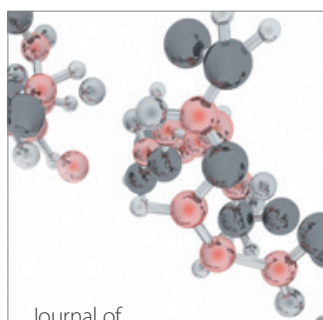

Analytical Methods

in Chemistry

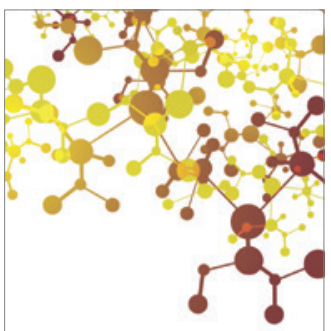

Journal of

Applied Chemistry

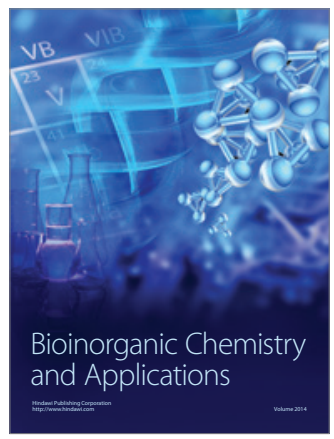

Inorganic Chemistry
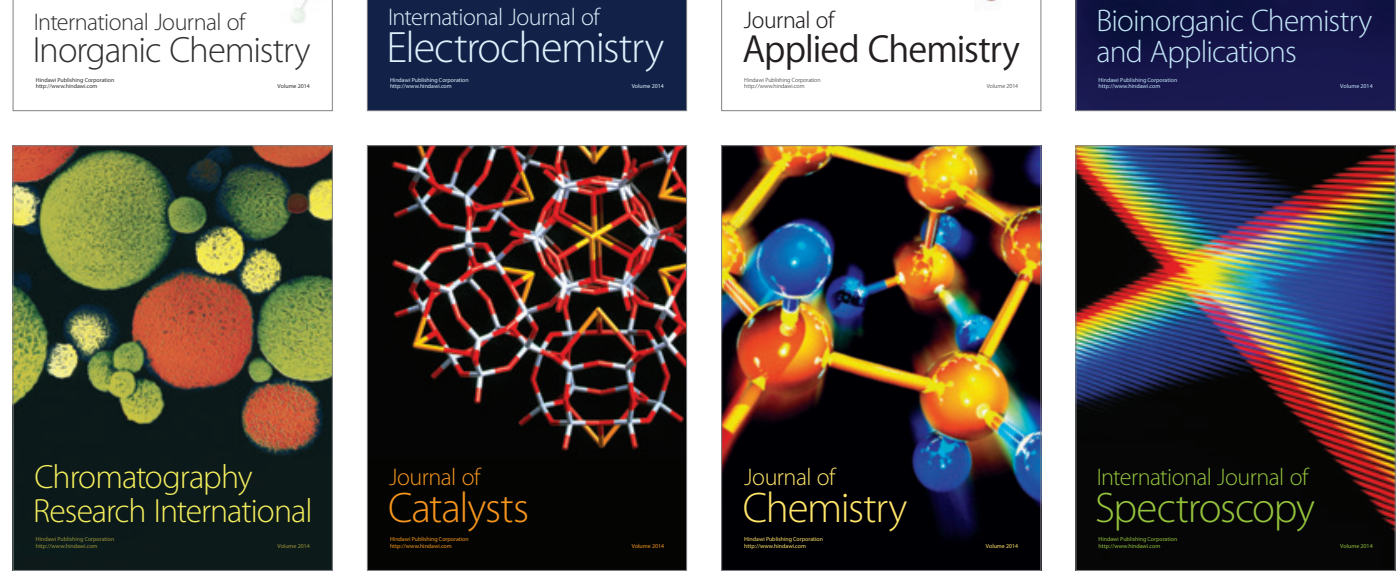